\title{
The OPCW and the industry: are there any obligations?
}

\section{Opinion}

The Organization for the Prohibition of Chemical Weapons is an organization devoted to the destruction of all the chemical weapons over our world, to prevent the reemergence of this weapon of mass destruction and to prevent the abuse or misuse of dual-use chemical compounds or technologies. This activities of the OPCW are determined by the Chemical Weapons Convention (CWC), an international agreement signed and ratified by 192 countries (and one that in the next few days will be doing the same), representing more than $98 \%$ of the world's population. Among many other activities, there are some that have a great importance for the chemical related industries.

\section{Declarations}

The Convention establishes for each State Party, the obligation to deliver to the OPCW an initial declaration related to the situation of that State, regarding chemical weapons (current, old and abandoned), facilities related to chemical weapons and riot control agents. Subsequently, they must submit an annual declaration that complements the initial one. The National Authority of the State Party is an institution that constitutes the link between the State Party and the OPCW, which collaborates with the elements of the national industry for the filling of the declarations and their delivery in time and form to the Technical Secretariat of the Organization. For the due fulfillment of this part, we have a Statement Manual that includes all the forms to be filled out by each instance that declares, related to industrial facilities, transfers of substances included in the Lists and everything related to industrial facilities that the drive The Manual of Declarations is updated regularly: the first version was published in 0 and two revised versions have been published, in 04 and in 0 7. The National Authority must gather all the declarations and send them to the Technical Secretariat for review and filing. The National Authority has the opportunity to make this delivery to the Technical Secretariat, by electronic means through a secure information exchange system.

In very specific cases, statements must be made about installations dedicated to the destruction of chemical weapons. So, as we have seen, the chemical related industries that uses any chemicals listed in the Schedules 1, 2 or 3 that are annexes to the CWC, or any organic substances that contain sulphur, fluor or phosphorous elements, must deliver an annual declaration regarding the production, consumption, sale, purchase or any other transaction that involves such chemicals, depending on the quantities of each substance. After de declarations are reviewed at the OPCW Headquarters (by the Technical Secretariat), the OPCW has the possibility to perform ordinary inspections of facilities directly related to chemical weapons and industrial facilities that use some chemical substances that could be used for prohibited

\author{
Volume 6 Issue I - 2018
}

Benjamin Ruiz Loyola
Faculty of Chemistry, UNAM

Correspondence: Benjamin Ruiz Loyola, Faculty of Chemistry, UNAM, Av. Universidad 3000, Coyoacan, 045 I 0, Cd. Mx. Mexico, Email rloyola@unam.mx

Received: December 18, 2017| Published: January 09, 2018

purposes (chemical weapons) or for authorized (peaceful) purposes; To carry out these inspections, the OPCW has a body of more than 100 inspectors from many different countries, experts in various areas of knowledge and who have been selected and trained for this activity. The State Party that will receive the inspection is informed of the names of the inspectors and their assistants, since the State Party may object in writing to certain inspectors, unless the inspection had already been notified without prior objections. The inspectors grant the inspectors privileges and immunities of a diplomatic nature, extensive to their work units, accommodation, work equipment and samples taken during the inspection. The declarations are studied and, in case of controversy, a new inspection is scheduled. The final inspection report will contain only specific data on compliance with the Convention. It will also contain information on how the inspected State Party cooperated with the inspection team. The report will be presented to the inspected State Party for comments, which will be attached to the report. The final report, together with the observations of the inspected State Party, will be presented to the Director General 0 days after the inspection at the latest. If necessary, the Director General may request clarifications from the inspected State Party. If this is not the case, the Director General will issue a letter of termination, officially finishing the inspection process.

So, even if you have never been engaged in any chemical weapons situation, if you work in any industry that deals with chemicals listed in the OPCW's schedules, you are intimately related to the OPCW and should know the Declarations Manual, for your own benefit.

\section{Acknowledgements}

None.

\section{Conflict of interest}

Author declares that there is no conflict of interest. 